\title{
Numerical studies on slope stability in torrential rainfall by using two-phase flow analysis
}

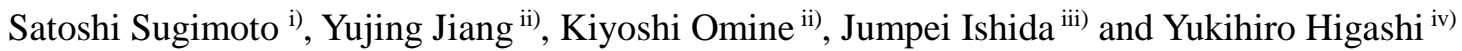 \\ i) Assistant Professor, Department of engineering, Nagasaki University, 1-14, Bunkyo, Nagasaki, 852-8521, Japan. \\ ii) Professor, Department of engineering, Nagasaki University, 1-14, Bunkyo, Nagasaki, 852-8521, Japan. \\ iii) Graduate Student, Graduate School of engineering, Nagasaki University, 1-14, Bunkyo, Nagasaki, 852-8521, Japan. \\ iv) Geoscience Research Laboratory, 3-1-6 JM Bld. 4F, Yamato Higashi, Yamato, Kanagawa, 242-0017, Japan.
}

\begin{abstract}
In recent years, localized torrential rainfall caused by abnormal weather happens frequently. It triggered numerous sediment disasters as slope failure. During heavy rainfall, it is estimated that degree of saturation increases rapidly in the ground with water flow. It may cause pore air occluding with rapid water flow in some cases. Because natural slope is often unsaturated, it is required to consider effect of pore air pressure. In this study, coupled stress-flow analysis is performed by calculating two-phase flow considered effect of pore air pressure. Failure mechanisms of slope are examined by decreasing effective stress, which is induced by increases of pore water and air pressure. It is discussed on slope stability by the case studies focused land features and rainfall intensity under like these conditions. The calculation results could be divided two prominent failure types. One is resulted from decreasing effective stress caused by rise of ground water level under the condition of gentle slope. And another one is resulted from gravitational sliding caused by increasing soil mass weight with short-time heavy rainfall under the condition of steep slope.
\end{abstract}

Keywords: two-phase flow, coupled stress-flow, pore pressure, slope failure, torrential rainfall

\section{INTRODUCTION}

In recent years, localized torrential rain caused by abnormal weather happens frequently. Torrential rainfall triggered numerous sediment disasters. Failure may happen even in some rigid regions of slope due to seepage of rainwater in the ground. Failure regions increase rapidly once collapse starts, which threats people's life and safety of infrastructures. If there is a technique to detect a slope which has potential of failure or may present behavior of failure, it would greatly contribute to slope disaster preventions.

Some previous studies have been performed to elucidate slope failure mechanisms. For example, in the study of Nishida ${ }^{1)}$ and others ${ }^{1)-3)}$, pore pressure caused by infiltration of rainfall was calculated firstly. And then, slope stability was analyzed using a limit equilibrium method based on their calculated results. Since the limit equilibrium method cannot estimate deformation of slope, slope analysis by finite element method (FEM) was also conducted. On the other hand, Sai and others ${ }^{4)}$ compared differences between limit equilibrium method and elastic-plastic FEM ${ }^{4) 5}$ in slope stability analysis. It is difficult to calculate large deformation and simulate mechanical behaviors of slope failure, since coupling of stress-flow are negligible in limit equilibrium method. However, FEM can solve these problems, based on infinitesimal deformations. Slope failure and landslide simulation are also studied with finite difference method (FDM) by other researchers ${ }^{6) 7}$.

These studies have tried to elucidate failure mechanisms of slope caused by water seepage. However, effect of pore air in the ground is not considered in their researches. During heavy rainfall, saturation of soil/rock near a boundary of atmosphere and ground rises rapidly, although pore air is occluded in the ground. Effective stress decreases due to rainfall and may cause slope failure. Because real natural slope is often unsaturated, it is required to consider effect of pore air pressure. Also, prediction of slope failure should be focused on some important aspects, for example, prediction of failure form, location of hazardous failure and so on.

In this study, coupled stress-flow analysis is performed by calculating two-phase flow considered effect of pore air pressure. Failure mechanisms of slope are examined by decreasing effective stress, which is induced by increases of pore water and air pressure. It is discussed on slope stability by the case studies focused land features and rainfall intensity under like these conditions. 


\section{OVERVIEW OF ANALYSIS ${ }^{8)}$}

Finite difference method (FDM) and finite element method (FEM) are mentioned as typical numerical analysis methods which regard target ground as a continuous media. Since it is easy to formulate the constitutive laws by finite difference method, it is more usable than finite element method when calculating stress-strain with increment of time using an explicit method. In this study, finite difference method based on large deformation theory (code name: FLAC) was used to simulate local instability of a slope. FLAC is the finite difference method analysis code based on an explicit method, which was developed by P. A. Cundall and others. FLAC not only has function of seepage analysis for porous media, but also has capability of stress-flow analysis.

\subsection{Mathematical formulation}

\section{(1) Transport laws}

Two-phase flow logic in FLAC embodies the following laws.

Wetting and non-wetting fluid transport are described by Darcy's law, as shown in Eq. (1), (2)

$$
\begin{gathered}
q_{i}^{w}=-k_{i j}^{w} \kappa_{r}^{w} \frac{\partial}{\partial x_{j}}\left(P_{w}-\rho_{w} g_{k} x_{k}\right) \\
q_{i}^{g}=-k_{i j}^{w} \frac{\mu_{w}}{\mu_{g}} \kappa_{r}^{g} \frac{\partial}{\partial x_{j}}\left(P_{g}-\rho_{g} g_{k} x_{k}\right)
\end{gathered}
$$

where $k_{i j}$ is saturated mobility coefficient, $k_{r}$ is relative permeability for fluid, $\mu$ is dynamic viscosity, $P$ is pore pressure, $\rho$ is fluid density and $g$ is gravity. $w$ and $g$ of subscript express wetting and non-wetting each. Relative permeabilities are related to $S_{w}$ by empirical laws of the van Genuchten form, as shown in Eq. (3), (4)

$$
\begin{aligned}
& \kappa_{r}^{w}=S_{e}^{b}\left[1-\left(1-S_{e}^{1 / a}\right)^{a}\right]^{2} \\
& \kappa_{r}^{g}=\left(1-S_{e}\right)^{c}\left[1-S_{e}^{1 / a}\right]^{2 a}
\end{aligned}
$$

In those laws, a,b and c are constant parameters and $S_{e}$ is effective saturation. Effective saturation is defind as Eq. (5)

$$
S_{e}=\frac{S_{w}-S_{r}^{w}}{1-S_{r}^{w}}
$$

where $S_{r}{ }^{w}$ is residual wetting fluid saturation.

In FLAC, capillary pressure law is of the van Genucheten form as shown in Eq. (6)

$$
P_{c}\left(S_{w}\right)=P_{0}\left[S_{e}^{-1 / a}-1\right]^{1-a}
$$

For slightly compressible fluids, balance relations are shown in Eq.(7),(8)

$$
\begin{aligned}
& \frac{\partial \zeta_{w}}{\partial t}=-\frac{\partial q_{i}^{w}}{\partial x_{i}}+q_{v}^{w} \\
& \frac{\partial \zeta_{g}}{\partial t}=-\frac{\partial q_{i}^{g}}{\partial x_{i}}+q_{v}^{g}
\end{aligned}
$$

where $\zeta$ is variation of fluid concent, and $q_{v}$ is volumetric fluid souce intensity. (10)

The constitutive laws for fluids are shown in Eq. (9),

$$
\begin{aligned}
& S_{w} \frac{\partial P_{w}}{\partial t}=\frac{K_{w}}{n}\left[\frac{\partial \zeta_{w}}{\partial t}-n \frac{\partial S_{w}}{\partial t}-S_{w} \frac{\partial \varepsilon}{\partial t}\right] \\
& S_{g} \frac{\partial P_{g}}{\partial t}=\frac{K_{g}}{n}\left[\frac{\partial \zeta_{g}}{\partial t}-n \frac{\partial S_{g}}{\partial t}-S_{g} \frac{\partial \varepsilon}{\partial t}\right]
\end{aligned}
$$

where $K_{w}, K_{g}$ are fluid bulk moduli, and $\varepsilon$ is volumetric strain.

\section{(2) Balance of Momentum}

Balance equation is shown in Eq. (11)

$$
\frac{\partial \sigma_{i j}}{\partial x_{j}}+\rho g_{i}=\rho \frac{d \dot{u}_{i}}{d t}
$$

where $\rho$ is bulk density and $\dot{u}$ is velocity. For two-phase flow calculations we have

$$
\rho=\rho_{d}+n\left(S_{w} \rho_{w}+S_{g} \rho_{g}\right)
$$

where $\rho_{w}, \rho_{g}$ are fluid densities, and $\rho_{d}$ is matrix dry density.

For two-phase flow, change in effective stress is difind as Eq. (13), (14)

$$
\begin{aligned}
& \sigma_{i j}^{\prime}=\sigma_{i j}-\bar{P} \delta_{i j} \\
& \bar{P}=S_{w} P_{w}+S_{g} P_{g}
\end{aligned}
$$

where $\sigma_{i j}^{\prime}$ is change in effective stress, $\sigma_{i j}$ is change in total stress.

\subsection{Determination of slope instability in coupled analysis}

Determination of slope instability in stress-flow annalysis is carried out by maximum unbalance force ratio $R_{\text {unbal }}$ shown in Eq. (16)

$$
R_{\text {unbal }}=\frac{F_{\max }}{F}
$$

Maximum unbalance force ratio is used to estimates slope stability. Unbalance force ratio is ratio of maximum force acted on nodes of any meshes to force acted on neighboring it in whole model. The maximum value of unbalance force ratio is calculated for each step. When its value is low, force balances at all nodes. Experientially, if unbalance force ratio is less than or 
eaqual to $1.0 \times 10^{-4}$, then it is stable state, else it is unstable state.

\section{EVALUATION OF VALIDITY OF THIS MODEL BY THE ONE-DIMENSIONAL SEEPAGE ANALYSIS}

The two-phase flow analysis model is confirmed by performing the reproduction analysis of one-dimensional seepage flow model test. Testing model of one-dimensional seepage flow model test is shown in Fig. 1.

Analysis model has the same dimensions as testing model and measurement points of pore pressure are shown in Fig. 2. Water which is set to have a rainfall intensity of $50 \mathrm{~mm} / \mathrm{h}$ is supplied from the top of the testing model. The permeability of the testing model is $1.87 \times 10^{-5} \mathrm{~m} / \mathrm{sec}$. One-dimensional seepage flow analysis and model test are conducted under a non-drainage conditions on the bottom.

Pore water pressure is measured at the bottom and center of the testing model. Tensiometer measure the negative pore water pressure, while pore pressure meter measure positive pore water pressure.

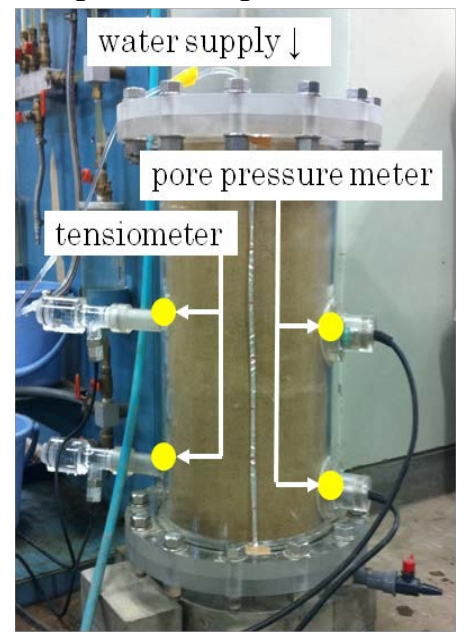

Fig. 1. Model of one-dimensional seepage flow.

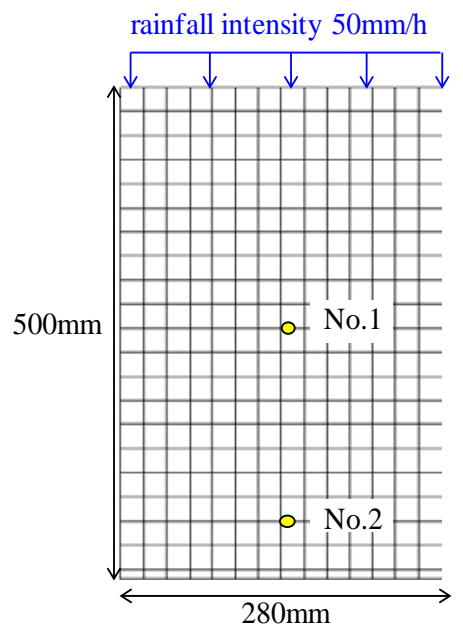

Fig. 2. Numerical simulation model.
Changes of pore water pressure during the test and analysis are shown in Fig. 3. Both analysis and test show that value of pore water pressure become negative after starting to supply water. Finally, pore water pressure becomes constant after rapidly increases. Initiation time of pore water pressure positive is different. In addition, there is a different increase tendency for pore water pressure. This is because that numerical model is treated as a homogeneous material in the analysis, however, in the test, the model is inhomogeneous. Thereby, it is not possible to take into account the numerical analysis for a complex behaviour of seepage flow at present. However, the increasing trends and convergence values of pore pressure have general similar characteristics.

\section{NUMERICAL SIMULATION ON SLOPE STABILITY}

\subsection{Simple slope model}

Fig. 4 shows numerical model of simple slope. Numerical model was created with varying slope angle $\left(\alpha: 20,30,40,50^{\circ}\right)$ and height of slope (H: 20, 40, 60, $80 \mathrm{~m})$. In addition, analysis was carried out by changing rainfall intensity (R: $25,50,75,100 \mathrm{~mm} / \mathrm{h}$ ) to consider effect of slope shape and rainfall intensity on stability of slope. The right side and bottom of model are impermeable layer. Physical properties used for the analysis is given from previous studies on the physical strength properties of decomposed granite soil ${ }^{9)}$. Physical properties are given to entire model such as shown in Table 1. Numerical model is elasto-plastic body to yielding in accordance with the Mohr Coulomb laws.

Procedure of simulation is described in the following. At first, reproduce the initial state by gravity analysis. Second, rainfall is given as a velocity head of the node at the boundary from the surface of slope. Third, coupled stress- flow analysis is carried out, and the slope instability is judged. If the slope is not destabilized when pore pressure in the model has reached a steady state, the slope is considered stable at all times.

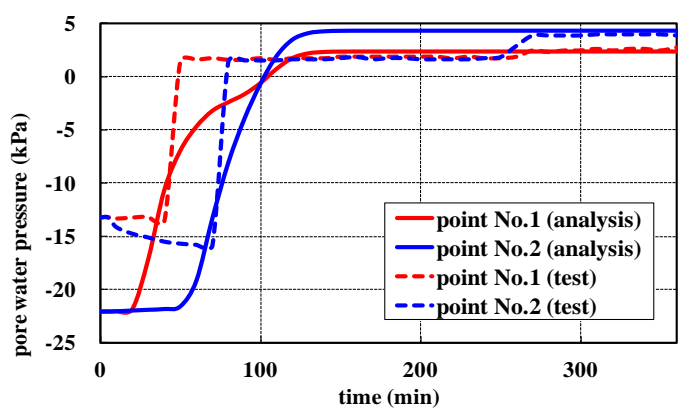

Fig. 3. Change of pore pressure. 


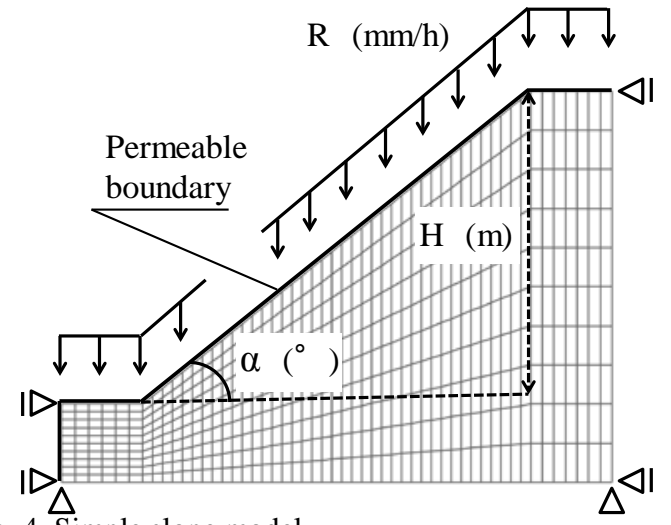

Fig. 4. Simple slope model.

Table 1. Input parameter.

\begin{tabular}{lc}
\hline Peameability $\mathrm{k}_{\mathrm{h}}(\mathrm{m} / \mathrm{sec})$ & $1.0 \times 10^{-5}$ \\
\hline Porosity $\mathrm{n}$ & 0.4 \\
\hline Elastic modulus E $(\mathrm{Mpa})$ & 200 \\
\hline Poisson's ratio $v$ & 0.3 \\
\hline Density $\rho\left(\mathrm{kg} / \mathrm{m}^{3}\right)$ & 1600 \\
\hline Cohesion c $(\mathrm{kPa})$ & 15.0 \\
\hline Friction angle $\varphi(\mathrm{deg})$ & 35.0 \\
\hline
\end{tabular}

Relationship between the slope shape and the time of failure occurrence for each rainfall intensity are shown in Table 2. Colored cell is a condition that slope was destabilized by rainfall. The time slope destabilized are shown in cells. Cells which are colored in black are under condition that slope was destabilized when gravity analysis carried out.

The time of failure occurrence become faster as rainfall intensity is greater. There is a difference of several tens of hours in the time of failure occurrence between the case of $50 \mathrm{~mm} / \mathrm{h}$ and $25 \mathrm{~mm} / \mathrm{h}$. However, if rainfall intensity is greater than $50 \mathrm{~mm} / \mathrm{h}$, there is no major difference in time of failure occurrence. There is a limit to possible penetration velocity, because coefficient of permeability in all of model is same property. It suggests there is a possibility that larger effect of rainfall intensity is given to destabilization of the slope, when coefficient of permeability is increased.

The time of failure occurrence becomes late as slope height increases, when the slope angle is smaller. Conversely, the time of failure occurrence becomes early as slope height increases, when the slope angle is larger. At the cells which are colored in dark in the Table 2, the time of failure occurrence is early than other. Simulation was carried out by applying rainfall intensity $50 \mathrm{~mm} / \mathrm{h}$ for the two type of slope models (Slope A: $\mathrm{H}=40 \mathrm{~m}, \alpha=30^{\circ}$ and Slope B: $\mathrm{H}=40 \mathrm{~m}, \alpha=50^{\circ}$ ). Variations of saturation and pore water pressure with increasing elapsed time after start of raining are shown in Fig. 5 and Fig. 6. In Fig. 5, water seepage is prevented by pore air, and it is confirmed that
Table 2. Relationship between the slope shape and the time of failure occurrence.

(a) $\mathrm{R}=25 \mathrm{~mm} / \mathrm{h}$

\begin{tabular}{|c|c|c|c|c|}
\hline $\mathrm{H}^{\alpha(\mathrm{m})}$ & 20 & 30 & 40 & 50 \\
\hline 20 & & & 250 & 225 \\
\hline 40 & & 377.5 & 250 & 25 \\
\hline 60 & & 410 & 215 & \multicolumn{1}{|c|}{} \\
\hline 80 & & 420 & 145 & \multicolumn{1}{|c|}{} \\
\hline
\end{tabular}

(b) $\mathrm{R}=50 \mathrm{~mm} / \mathrm{h}$

\begin{tabular}{|c|c|c|c|c|}
\hline $\mathrm{H}_{(\mathrm{m})}{ }^{\alpha\left(^{\circ}\right)}$ & 20 & 30 & 40 & 50 \\
\hline 20 & & & 222.5 & 202.5 \\
\hline 40 & & 320 & 222.5 & 20 \\
\hline 60 & & 360 & 195 & \\
\hline 80 & & 360 & 105 & \\
\hline
\end{tabular}

(c) $\mathrm{R}=75 \mathrm{~mm} / \mathrm{h}$

\begin{tabular}{|c|c|c|c|c|}
\hline $\mathrm{H}_{\mathrm{H}(\mathrm{m})}^{\alpha\left(^{(}\right)}$ & 20 & 30 & 40 & 50 \\
\hline 20 & & & 220 & 200 \\
\hline 40 & & 317.5 & 220 & 17.5 \\
\hline 60 & & 360 & 192.5 & \multicolumn{1}{|c|}{} \\
\hline 80 & & 360 & 100 & \multicolumn{1}{|c|}{} \\
\cline { 1 - 3 } & &
\end{tabular}

(d) $\mathrm{R}=100 \mathrm{~mm} / \mathrm{h}$

\begin{tabular}{|c|c|c|c|c|}
\hline \multicolumn{1}{|r|}{$\alpha\left({ }^{\circ}\right)$} & 20 & 30 & 40 & 50 \\
\hline 20 & & & 217.5 & 200 \\
\hline 40 & & 315 & 217.5 & 15 \\
\hline 60 & & 360 & 190 & \\
\hline 80 & & 360 & 97.5 & \multicolumn{1}{|c|}{} \\
\hline
\end{tabular}

saturation rises from the slope surface as enclosing air. In Fig. 6, pore water pressure increased from slope surface after starting to apply rainfall. Then, surface infiltration of rainfall penetration reaches the impermeable layer of the model bottom; finally, pore water pressure rises from the model bottom.

Distribution of shear strain of Slope A at the time of failure occurrence is shown in Fig. 7. Fig. 8 shows Mohr's stress circle of elements which shear deformation is outstanding at after start of rainfall and time of failure occurrence. Mohr's stress circle is not contact with the destruction criterion line, immediately after start of rainfall. It is in contact with the destruction criteria line in form of effective stress is reduced at the time of failure occurrence. In the case of small slope angles, it is considered effective stress is reduced by pore water pressure to rise from the bottom of the model, and reach to failure. It is considered that time of failure occurrence become late, because surface infiltration that reaching model bottom becomes slow as height of the slope rises. In addition, in the case of large slope angles, safety factor of the slope is small already for stress is concentrated on toe of slope part. It is thought that influence of physical shape may cause slope failure separately from reduction of effective stress due to rainfall infiltration. 


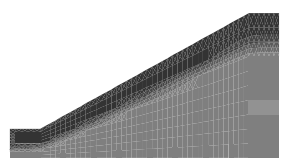

50 hours

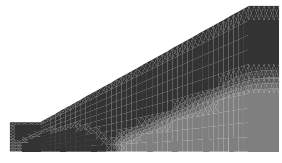

150 hours

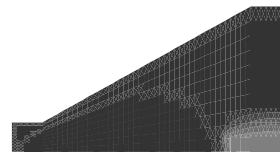

250 hours

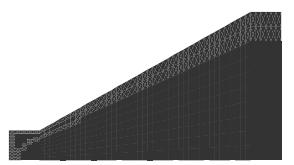

350 hours

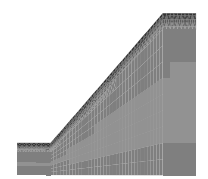

5 hours

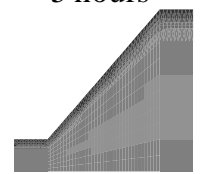

10 hours

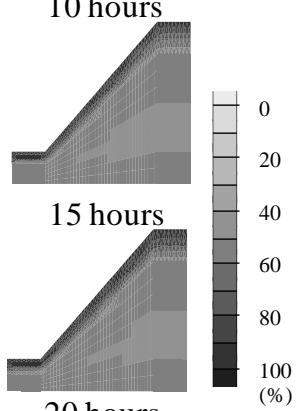

20 hours
Fig. 5. Variations of saturation.

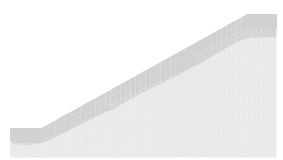

50 hours

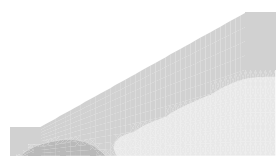

150 hours

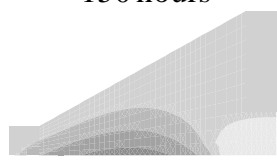

250 hours

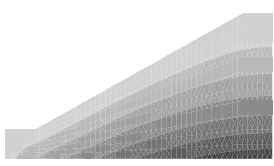

350 hours

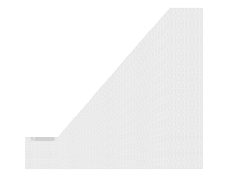

5 hours

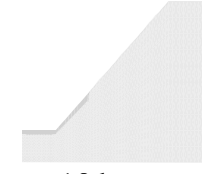

10 hours

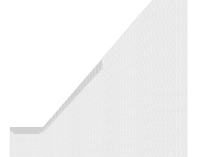

20 hours

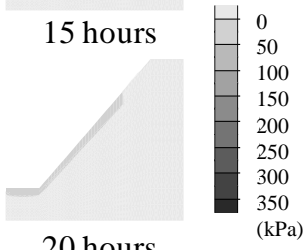

Fig. 6. Variations of pore pressure.

Distribution of shear strain of Slope B at the time of failure occurrence is shown in Fig. 9. Fig. 10 shows Mohr's stress circle of elements which shear deformation is outstanding at after start of rainfall and time of failure occurrence. From Fig. 10, Mohr's stress circle after start of rainfall is getting in contact with the destruction criterion line already, it can be seen that it is already unstable slope shape. In addition, it is getting in contact with the destruction criteria line in the form of Mohr's stress circle is increased due to increase of principal stress in the time of failure occurrence. From Fig. 10, it can be seen that saturation of slope surface layer rise sharply after start of rainfall. It is considered sliding power of soil mass is increased in order to soil

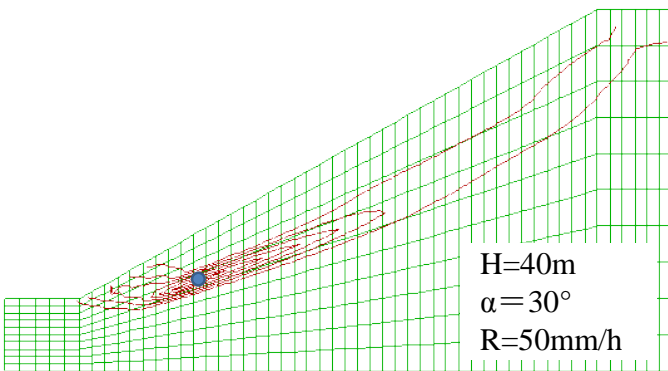

Fig. 7. Distribution of shear strain (Slope A).

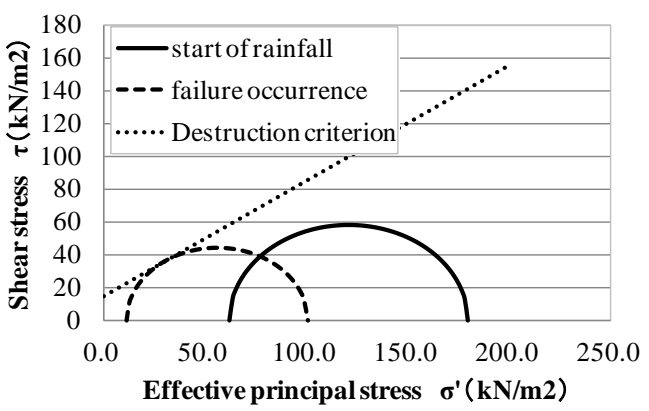

Fig. 8. Mohr's stress circle (Slope A).

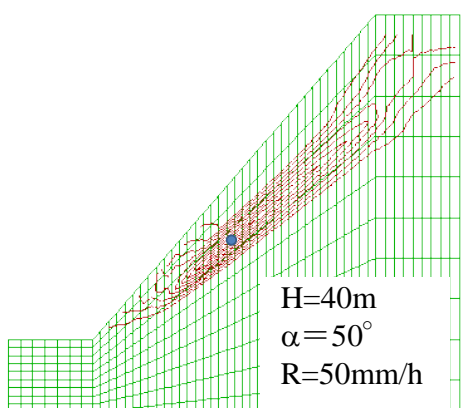

Fig. 9. Distribution of shear strain (Slope B).

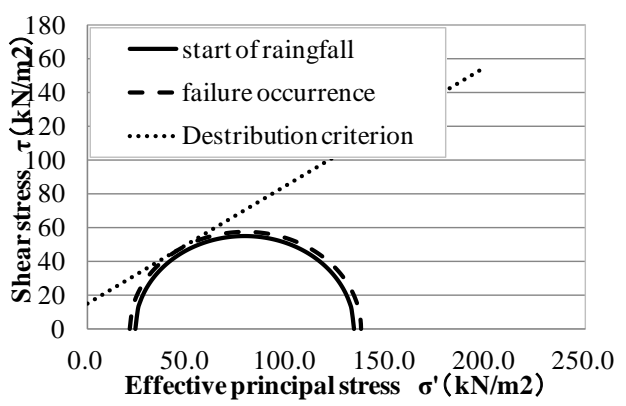

Fig. 10. Mohr's stress circle (Slope B).

mass own weight due to penetration of rainfall increases as height of slope rises. As a result, time of failure occurrence becomes faster.

\subsection{Calculation of sediment volume of failure}

For prediction of disaster scale of landslides, estimates sliding surface when the slope become failure, and calculate sediment volume of collapse. Fig. 11 shows a diagram of when Slope A is unstable. Vector in the Figure is displacement vector, and contour is maximum shear strain distribution. Since it is possible to confirm displacement occurs largely on elements 


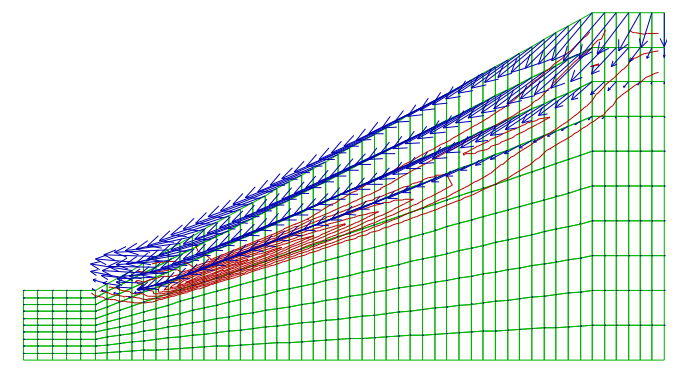

Fig. 11. Displacement vector and distribution of shear strain.

which shear deformation is outstanding, it is calculated as sediment volume of failure range shown in Fig. 12. Since this simulation is a two dimensional analysis, sediment volume is calculated in units per depth. The relationship between sediment volume and slope angle is shown in Fig. 13. As height of slope increases, sediment volume of collapse also has increased. Collapse sediment volume is maximum when slope angle of 30deg in 40,60, 80m slope height. Slope angle increases, it is confirmed that sediment volume is decreasing. In the case of small slope angle, it is thought that effective stress was decreased by increasing pore pressure from the impermeable layer may cause unstable of slope. As a result, it is considered that sliding surface is occurs deep from the slope surface, and sediment volume of collapse is increased. In the case of large slope angle, it is thought that soil mass weight was increased by increasing saturation from slope surface may cause unstable of slope. As a result, it is considered that only the surface layer of the slope becomes unstable and sediment volume of collapse is decreased.

\section{CONCLUSIONS}

In this study, case study was carried out by using numerical simulation to estimate relation between slope shape and rainfall intensity. As a result, there are two factors to cause slope to be unstable. For the case of small slope angle, the results show that effective stress was decreased by increasing pore pressure from the impermeable layer, making the slope unstable. In other case of large slope angle, it is thought that the soil mass weight was increased by increasing saturation from slope surface, which may cause slope unstable, too.

In this study, ground of slope was treated as homogeneous, and simulation was carried out without considering existence of groundwater. However real ground has a weathered soil layer on the surface, and groundwater is also presented to vicinity of the slope surface. Numerical simulation should be carried out in consideration of their effects. In future, we are going to carry out case study for data storage, and lead to creation of landslide disaster hazard map.

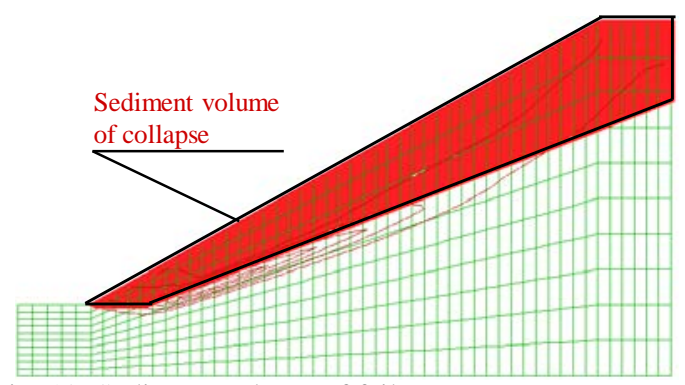

Fig. 12. Sediment volume of failure.

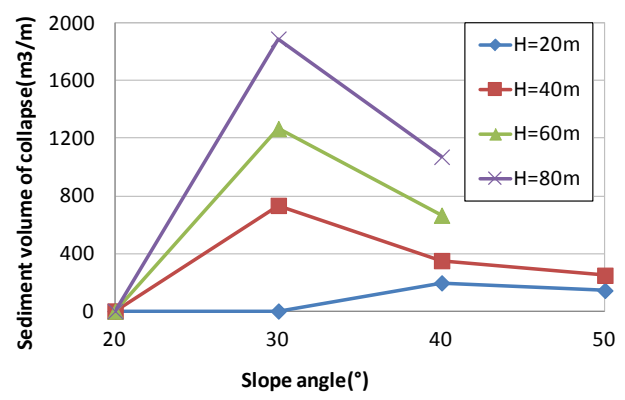

Fig. 13. Relationship between sediment volume of collapse and slope shape.

\section{REFERENCES}

1) Yoshichika Nishida, Norio Yagi, Mikio Futaki : Pore Pressure Caused by Rain Water Permeation and Stability of Earth Slope, Proceedings of Japan Society of Civil Engineers, No.262, pp.91-100, 1997.(in Japanese)

2) Norio Yagi, Ryuichi Yatabe, Koji Yamamoto : Slop Failure due to Seepage of Rain Water, Proceedings of Japan Society of Civil Engineers, No.330, pp.107-114, 1983. (in Japanese)

3) Ryuichi Yatabe, Meiketsu Enoki, Norio Yagi : Comparative Consideration on Slope Stability Analysis during Seepage of Rainfall, Landslides-Journal of Japan Landslide Society, Vol.22, No.4, pp.1-7, 1986. (in Japanese)

4) Fei Sai, Keizo Ugai, Wenfeng Huang : Slope stability analysis: Comparisons between limit equilibrium methods and elastoplastic finite element method, Landslides-Journal of the Japan Landslides Society, Vol.39, No4, pp.9-16, 2003. (in Japanese)

5) Fei Sai : Fundamental theories of FEM for landslide analysis, Journal of the Japan Landslides Society, Vol.40, No.5, 2004. (in Japanese)

6) Mitsuo Nakagawa, Yujing Jiang : Prediction of Slope Failure by Large Strain Analysis, Proceedings of the 35th symposium on rock mechanics, pp.109-114, 2006. (in Japanese)

7) Mitsuo Nakagawa, Masao Yamada : Application for large Displacement Landslides Simulation by Using Finite Difference Method, Journal of the Japan Landslides Society, Vol.44, No.6, 2008. (in Japanese)

8) Itasca Consulting Group, Inc. : FLAC User's Manual, Fluid-Mechanical Interaction, 2011.

9) Kazuhiko Nishida, Chiaki Aoyama: Classification System of Decomposed Granite Soil in Undisturbed State, Proceedings of Japan Society of Civil Engineers, No.352, pp.159-168, 1984. (in Japanese) 